\title{
A DUPLICATION dup(4)(q28q35.2) DE NOVO IN A NEWBORN
}

\author{
Iveta Cernakova ${ }^{\mathrm{a}}$, Marta Kvasnicova ${ }^{\mathrm{b}}$, Zuzana Lovasova ${ }^{\mathrm{b}}$, Nora Badova $^{\mathrm{b}}$, Jiri Drabek ${ }^{\mathrm{c}}$, \\ Katerina Bouchalovac ${ }^{c}$, Radek Trojanec ${ }^{c},{ }^{*}$ Marian Hajduch ${ }^{\mathrm{c}}$
}

\author{
a Institute of Biology and Medical Genetics, General Faculty Hospital and The $1^{\text {st }}$ Faculty of Medicine, Charles University, \\ Albertov 4, 12800 Prague 2, Czech Republic \\ b Department of Clinical Genetics, Roosewelt Hospital, 97515 Banska Bystrica, Slovak Republic \\ c Laboratory of Experimental Medicine, Department of Paediatrics, Faculty of Medicine, Palacky University and University \\ Hospital in Olomouc, Puskinova 6, 77520 Olomouc, Czech Republic \\ e-mail:hajduchm@atlas.cz
}

Received: March 21, 2006; Accepted: April 18, 2006

Key words: Duplication $4 q$ syndrome/Nijmegen breakage syndrome/Cytogenetics/G-band technique/Fluorescence in situ hybridization (FISH)/Polymerase chain reaction (PCR)

We report here a case of a newborn with hypotrophy and somatic stigmatization: microcephaly, facial dysmorphism, heart defect and immunodeficiency syndrome. The proband's karyotype was 46,XY,dup(4)(q28q35.2) de novo with chromosomal breaks in $4 \%$ of metaphases. We demonstrate the usefulness of a combination of physical examination, classical cytogenetics, FISH and PCR techniques in order to establish correct diagnosis because of overlap of some clinical and cytogenetic features of Nijmegen breakage syndrome (NBS) and duplication 4q in our patient. Although FISH technique detected translocation $\mathrm{t}(14 \mathrm{q} ; 21 \mathrm{q})$ in 4 metaphases, deletion $657 \mathrm{del} 5$ in exon 6 of the NBS1 gene associated with NBS in Slavic population was not confirmed. We compare in this report similarity of the clinical picture of our patient, NBS cases and other patients carrying a duplication of the distal part of $4 \mathrm{q}$ as described in the literature.

\section{INTRODUCTION}

Duplication of the long arm of chromosome 4 has been already described in more than 60 patients $^{1,2}$. Most of them result from the meiotic segregation of a parental balanced translocation and associate with a partial monosomy of various segments of other chromosomes. Patients with partial trisomy $4 \mathrm{q}$ have variable clinical stigmatization, which is both related to the size of duplicated segment of the chromosomal arm $4 \mathrm{q}$ and to specific associated monosomy. A review of the literature ${ }^{2}$ revealed approximately 20 cases of a pure duplication of $4 \mathrm{q}$ spanning the region from q12 to $\mathrm{q} 35$. Although simple or pure forms of duplications are less common they serve as a basis for a better understanding of relationships between chromosomal anomalies and their clinical manifestations.

In this communication we describe clinical, cytogenetic, FISH and PCR findings in a male newborn with an overlap in some clinical and cytogenetic features of Nijmegen breakage syndrome and duplication $4 \mathrm{q}$. We illustrate here the usefulness of the combined views of the clinical geneticist, the cytogeneticist and the molecular geneticist in establishing the correct diagnosis. To our knowledge this is the second case of the pure de novo duplication $4 \mathrm{q}$.

\section{MATERIAL AND METHODS}

Cytogenetic and FISH analysis were performed on cultured PHA-stimulated peripheral blood lymphocytes of the propositus and his parents. Classical cytogenetics was carried out using G-banding. The whole chromosome painting probes 4, 7, 14 and 21 (Vysis) and chromosome specific telomeric probe $4 \mathrm{q}$ (Vysis) were used for detection of (the) suspected rearrangements by FISH.

PCR diagnosis was performed using a DNA extracted by salting-out method from peripheral blood as described previously $^{3}$.

\section{RESULTS}

\section{Clinical report}

The boy was born in the $40^{\text {th }}$ week of physiologic pregnancy. His birth weight was $2600 \mathrm{~g}$ and his length was 52 $\mathrm{cm}$. The child was referred for genetic counselling at the age of 1 month because of somatic stigmatisation.

The newborn was hypotrophic and manifested slight hypertonic syndrome. Physical examination at the age of 1 week revealed microcephaly with head circumference of $31 \mathrm{~cm}$ (- $4 \mathrm{SD})$. The facial features included antimongoloid slanted palpebral fissures, epicanthic folds, strabismus, broad nasal bridge, prominent beaked nose with anteverted nostrils, low-set malformed ears, high arched palate, micrognathia and a pigmented naevus in 


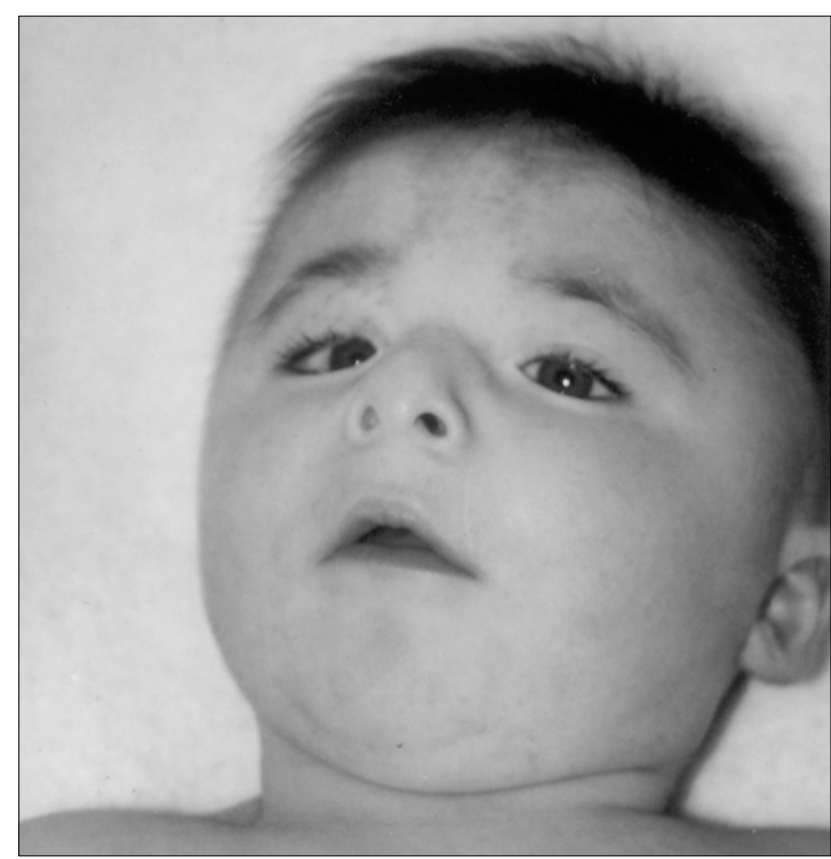

Fig. 1. Photography of reported patient aged 7 months.

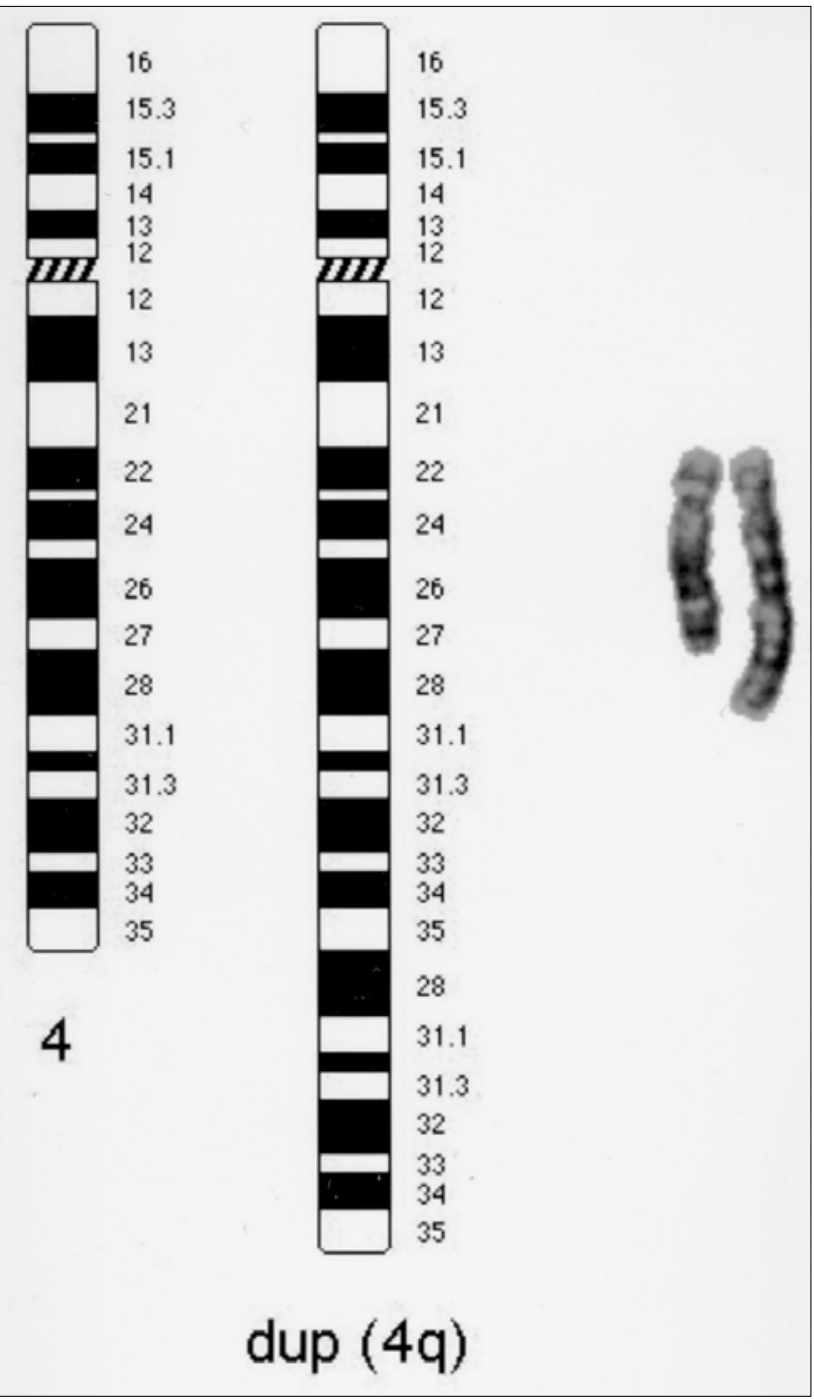

Fig. 2. Idiograms of the normal and abnormal chromosome 4 (left) and partial G - banded karyotype. the occipital area. Other findings included slight bilateral contractures of the knee and bilateral coloboma of optic papilla. The patient also suffered from congenital heart defect - foramen ovale apertum and immunodeficiency syndrome.

A follow-up physical examination at the age of 7 month confirmed microcephaly (head circumference was $39 \mathrm{~cm}$, i.e - 3.6 SD) with the same dysmorphic features (Fig. 1). Moderate psychomotor delay was observed (developmental age estimated at 3 to 4 months). However, there was no growth retardation.

The propositus is the second child of young, healthy and unrelated parents (gravida 2, para 2). The first child of the parents is a healthy daughter. There was no previous history of manifestation of any inherited developmental defects or mental retardation in the family. Several malignancies have occurred in previous generations.

\section{Classical cytogenetic analysis}

Cytogenetic and FISH analyses were performed on cultured PHA-stimulated peripheral blood lymphocytes of the propositus and his parents. The lymphocyte culture showed a low mitotic index. The karyotype was 46,XY,dup(4)(q28q35.2)de novo with chromosomal breaks in $4 \%$ of the metaphases. Both parental karyotypes were normal. Repeated cytogenetic investigation of the propositus at the age of 7 months revealed structural chromosomal aberrations in $2 \%$ of the metaphases.

\section{Fluorescence in situ hybridization}

FISH analysis was performed on the propositus on the basis of classical cytogenetics using the whole chromosome painting probes 4, 7, 14 and 21 for detection of the suspected rearrangements of these chromosomes (Vysis). We explored that additive chromosomal material originated from chromosome 4 by FISH technique. Using the chromosome-specific telomeric probe $4 \mathrm{q}$ (Vysis), we detected only one signal on both the normal and abnormal chromosome 4. Translocation $\mathrm{t}(14 \mathrm{q} ; 21 \mathrm{q})$ was found in 4 of 5 examined metaphases by FISH using the painting probes 14 and 21 . The final karyotype of the patient was 46,XY,dup(4)(q28q35.2)de novo, ish $\operatorname{dup}(4)(q 28 q t e r)(w c p 4+)$ (Fig. 2 and 3).

\section{DNA analysis}

PCR diagnosis of the suspected deletion 657 del5 in NBS1 gene located on the $8 \mathrm{q} 21$ chromosome was performed with DNA extracted by salting-out method from peripheral blood (Fig. 4). However, this Slavic mutation of NBS1 gene was not detected in our patient.

\section{DISCUSSION}

Rapid introduction of molecular biology techniques into routine medical practice significantly improves both specificity and sensitivity of clinical diagnostics. This case report is a typical example of the rare clinical syndrome, duplication $4 \mathrm{q}$, being diagnosed on the basis of molecular cytogenetics. 


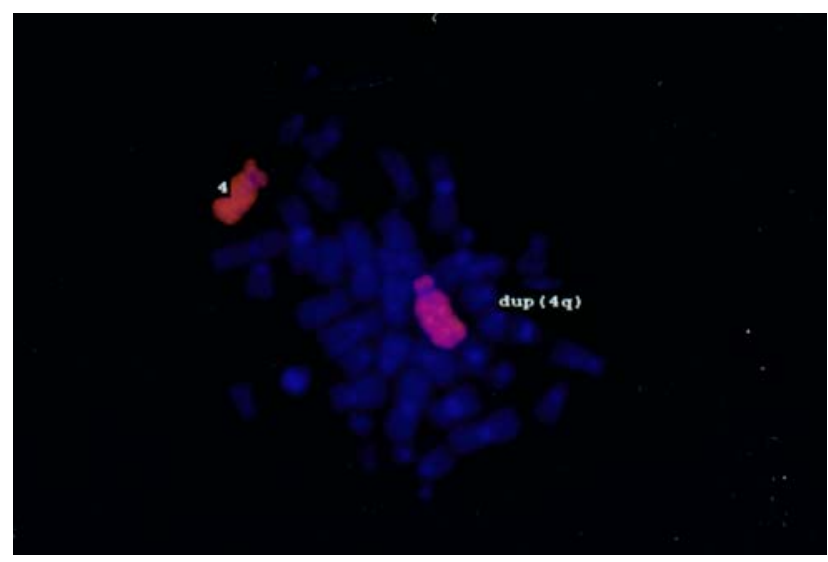

Fig. 3. FISH with whole chromosome painting probe 4 (Spectrum Orange, Vysis). Duplicated chromosome 4 is marked by arrows.

In our patient the large duplication of the distal part of $4 \mathrm{q}$ was detected by both the classical and molecular cytogenetic methods. Clinical and cytogenetic data are not currently sufficient to delineate a well-defined $\operatorname{dup}(4 q)$ syndrome. Reviews of the literature ${ }^{4-7}$ and the recent report ${ }^{2}$ confirm the phenotypic variability accompanying duplicated long arm of chromosome 4 . The wide phenotypic variability frequently reported in cases of duplication $4 \mathrm{q}$ could be related to the different size of the duplicated region, the location of the breakpoints and associated monosomies of the other chromosomal parts. Well-recognized features of this duplication are growth retardation, psychomotoric retardation of variable grade, seizures, large low-set ears and high nasal bridge. Most patients have microcephaly, short narrow palpebral fissures, hypotelorism and/or broad nasal bridge, short philtrum, micro-/retrognathia, short neck, abnormalities of the extremities, feet and toes and anomalies of the hip joints. Cardiac defects are reported in patients with a large duplicated segment. Generally, severe stigmatisation has been observed in patients with a larger degree of partial trisomy and in the patients with duplications spanning the distal part of $4 \mathrm{q}$. The segment $4 \mathrm{q} 32 \rightarrow \mathrm{qter}$ is genetically relatively deficient. However it contains the clinically important genes determining psychiatric illness, seizures and neurodegenerative disorders ${ }^{8}$. The reports of Goodman et al. ${ }^{9}$ and Maltby and Bennett ${ }^{10}$ show that the chromosomal segment $4 \mathrm{q} 31.1 \rightarrow \mathrm{q} 32.3$ can be duplicated with a minor or even no clinical effect.

Our proband has pure de novo duplication dup(4)(q28qter) confirmed by FISH. The duplicated region is relatively large and overlaps other previously reported cases. Celle et al. ${ }^{2}$ described monozygotic twins with partially discordant phenotypes and the duplication $4 \mathrm{q} 28.3 \rightarrow \mathrm{qter}$, originated from the unbalanced maternal translocation $\mathrm{t}(4 ; 22)(\mathrm{q} 28.3 ; \mathrm{p} 13)$. Thus our patient is the second case with the same partial trisomy and the first description of pure duplication without associated monosomy ${ }^{1,2}$. Comparison of the clinical manifestations

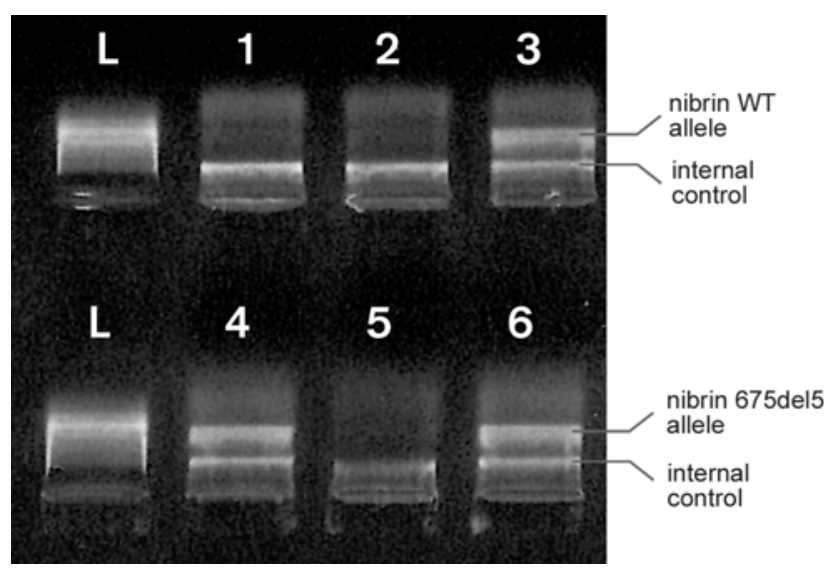

Fig. 4. Molecular diagnostics of 675 del 5 mutation of the nibrin gene using the sequence specific polymerase chain reaction with sequence specific primers. Shorter amplicon represents nibrin gene amplification product (wild type (WT) or $675 \mathrm{del} 5$ mutation) and longer internal control amplicon. L- DNA ladder (TopBio), 1- positive control for nibrin WT allele; 2- negative control for nibrin WT allele; 3- patient sample; 4- positive control for $675 \mathrm{del} 5$ mutation; 5 - negative control for $675 \mathrm{del} 5$ mutation allele; 6 - patient sample. $675 \mathrm{del} 5$ mutation in the patient was not confirmed.

in our patient and cases with pure duplication of $4 \mathrm{q}$ reported previously ${ }^{7,11-15}$ is summarized in Table 1 . Our patient demonstrates majority of clinical features according to the criteria established by Halal et al. ${ }^{7}$ and Jeziorowska et al. ${ }^{15}$. On the other hand, he has neither renal hypoplasia nor thumb anomalies, which are consistently associated with the duplication of the interstitial segment $4 \mathrm{q} 21 \rightarrow \mathrm{q} 22$, as suggested by Zollino et al. ${ }^{16}$.

Clinical features of $4 \mathrm{q}$ duplication in our newborn share a lot of similarities with Nijmegen breakage syndrome. Nijmegen breakage syndrome belongs to the group of inherited chromosomal instability syndromes. The disorder is an autosomal recessive in nature, characterized by growth and mental retardation, craniofacial dysmorphy, immunodeficiency, chromosomal instability, predisposition to lymphoid malignancies and radiosensitivity ${ }^{17}$. Varon et al. ${ }^{18}$ identified the NBS1 gene on chromosome $8 \mathrm{q} 21$. The gene encodes protein nibrin, which participates in DNA repair. Interestingly, the authors detected the deletion $657 \mathrm{del} 5$ in exon 6 of the NBS 1 gene in 46 out of 51 patients in the NBS register. This mutation, leading to the formation of truncated protein, was found to be of Slavic origin. However, in our patient mutation $657 \mathrm{del} 5$ was not detected, although it does not exclude other alterations in nibrin, since the whole gene was not sequenced.

The clinical diagnosis of Nijmegen breakage syndrome was suggested in the newborn because of his obvious microcephaly and immunodeficiency. Microcephaly is one of the major criteria of NBS. The head circumference at birth below the $3^{\text {rd }}$ percentile was observed in $75 \%$ of 
NBS patients. On the other hand, this cranial anomaly has been described in most of the patients with duplication of the distal segment of $4 \mathrm{q}$, although the immunodeficiency syndrome has never been reported in those cases. Repeated cytogenetic investigation revealed low mitotic activity of cultured peripheral lymphocytes, which is consistent with clinical immunodeficiency, and only $4 \% / 2 \%$ of chromosomal breaks/rearrangements, respectively. We also detected the rearrangement between the long arm of chromosomes 14 and 21 by FISH method. Chromosomal instability, which is basic characteristic of the Nijmegen breakage syndrome, occurred in our patient in a few metaphases only and it was probably coincidental. The growth of the child showed that the clinical features are more specific to duplication of $4 \mathrm{q}$ than to the NBS than was suspected prior to laboratory examination.

\section{CONCLUSION}

A newborn suspected from NBS was assessed using classical and molecular cytogenetics and karyotype 46,XY,dup(4)(q28q35.2)de novo was revealed. The diagnosis of supposed NBS was excluded by molecular PCR based diagnostics, although translocation $\mathrm{t}(14 \mathrm{q} ; 21 \mathrm{q})$ typical for this syndrome was found in 4 of 5 assessed metaphases using FISH.

\section{ACKNOWLEDGEMENTS}

This study was supported in parts by the Ministry of Education of the Czech Republic (MSM6198959216). The editorial help of Alec Oulton and Sergey Kouzmin is greatly appreciated.

\section{REFERENCES}

1. Borgaonkar DS. Chromosomal variation in man. A catalog of chromosomal variants and anomalies. New York: Wiley-Liss Inc. 1997.

2. Celle L, Lee L, Rintoul N, Savani RC, Long W, Mennuti MT, Krantz ID. (2000) Duplication of chromosome region 4q28.3- qter in monozygotic twins with discordant phenotypes. Am J Med Genet 94, 125-140.

3. Drábek J, Hajdúch M, Gojová L, Weigl E, Mihál V. (2002) Frequency of $657 \mathrm{del}(5)$ mutation of the NBS1 gene in the Czech population by polymerase chain reaction with sequence specific primers. Cancer Genet Cytogenet 138, 157-159.

4. Červenka J, Djavadi GR, Gorlin RJ. (1976) Partial trisomy 4q syndrome: a case report and review. Hum Genet 34, 1-7.

5. Yunis E, Giraldo A, Zuniga R, Egel H, Ramirez E. (1977) Partial trisomy 4q. Ann Genet 20, 243-248.

6. Stella M, Bonfante A, Ronconi G, Rossi G. (1979) Partial trisomy 4q. Two cases with a familial translocation $\mathrm{t}(4 ; 18)(\mathrm{q} 27 ; \mathrm{q} 23)$. Hum Genet 47, 245-251.

7. Halal F, Vekemans F, Chitayat D. (1991) Interstitial tandem direct duplication of the long arm of chromosome $4(\mathrm{q} 23 \rightarrow \mathrm{q} 27)$ and possible assignment of the structural gene encoding human aspartylglucosaminidase to this segment. Am J Med Genet 39, 418-421.

8. Riess O, Winkelmann G, Epplen JT. (1994) Toward the complete genomic map and molecular pathology of human chromosome 4 . Hum Genet 94, 1-18.

9. Goodman BK, Capone GT, Hennessey J, Thomas GH. (1997) Familial tandem duplication of bands q31.1 to q32.3 on chromosome 4 with mild phenotypic effect. Am J Med Genet 73, 119124.

10. Maltby EL, Barnes ICS, Bennett CP. (1999) Duplication involving band $4 \mathrm{q} 32$ with minimal clinical effect. Am J Med Genet 83, 431.

11. Vogel W, Siebers JW, Gunkel J. (1975) Uneinheitlicher Phänotyp bei Partialtrisomie 4q. Humangenetik 28, 103-112.

12. Fryns JP, van den Berghe H. (1980) Partial duplication of the long arm of chromosome 4. Ann Genet 23, 52-53.

13. Dutrillaux B, Laurent C, Forabosco A, Noel LB, Suerinc CE, Biemont MC, Cotton JB. (1975) La trisomie 4q partielle. A propos de trois observations. Ann Genet 18, 21-27.

14. Taylor KM, Francke U, Brown MG, George DL, Kaufhold M. (1977) Inverted tandem ("mirror") duplications in human chromosomes: inv dup 8p, 4q, 22q. Am J Med Genet 1, 3-19.

15. Jeziorowska A, Ciesla W, Houck GE, Jr, Yao XL, Harris MS, Truszczak B, Skorski M, Jakubowski L, Jenkins EC, Kaluzewski B. (1993) Cytogenetic and molecular identification of a de novo direct duplication of the long arm of chromosome $4(\mathrm{q} 21.3 \rightarrow \mathrm{q} 31.3)$. Am J Med Genet 46, 83-87.

16. Zollino M, Zampino G, Torrioli G, Pomponi MG, Neri G. (1995) Further contribution to the description of phenotypes associated with partial 4q duplication. Am J Med Genet 57, 69-73.

17. Seemanova E, Passarge E, Beneskova D, Houstek J, Kasal P, Sevcikova M. (1985) Familial microcephaly with normal intelligence, immunodeficiency and risk of lymphoreticular malignancies: a new autosomal recessive disorder. Am J Med Genet 20, 639-648.

18. Varon R, Vissinga R, Vissinga C, Platzer M, Cerosaletti KM. (1998) Nibrin, a novel DNS double-strand break repair protein, is mutated in Nijmegen breakage syndrome. Cell 93, 467-476. 